ORIGINAL PROF-2063

\title{
TRANS FATTY ACID;
}

A confounding risk factor in coronary heart disease

Fatima Yousaf Ali

ABSTRACT: Objectives: To find out the correlation between the consumption of trans fatty acid and fasting lipid profile $\&$ body mass index (BMI) in patients suffering from coronary heart disease. Study Design: Prospective, comparative clinical study. Study Site $\&$ Duration: This study was conducted at Shafakhana Sahib az Zaman Medical Hospital Quetta from April, 2007 to May, 2008. Material \& Methods: This comparative clinical trial was conducted on 50 patients $(n=50)$ to find out the correlation between the consumption of trans fatty acid and fasting lipid profile $\&$ body mass index (BMI) in patients suffering from coronary heart disease. Detail history about the use of Trans fats containing products was recorded. Patient's height and weight was recorded by standard calibrated standiometer. The fasting glucose and lipid profile was performed by overnight fasting of 12 hours. The patients was divided into group I ( $n=18)$, who used Trans fats free oil/ghee and group II $(n=32)$, who used trans fats containing ghee. The results of the two groups were compared and correlation of different variables was determined. Results: The study result shows that mean age $58.428 \pm 9.67721$ years, mean height 5.476 \pm .5899 feet, mean weight $61.5 \pm 4.8793 \mathrm{Kg}$ and mean BMI was $22.35 \pm 5.24195 \mathrm{Kg} / \mathrm{m} 2$. There was slightly higher value of BMI in group II. The comparison of serum lipid profile and glucose among the two groups shows that there is a correlation of Trans fatty acid with certain parameters like high density lipoprotein $(H D L)$ and total lipid with p-value of $0.027 \& 0.014$ respectively. Similarly serum cholesterol and low density lipoprotein (LDL) correlated with Trans fats lipid having both p- value of 0.000 . Conclusions: There is a correlation of Trans fatty acid with serum cholesterol, LDL, HDL and total lipid. The consumption of Trans fatty acid has shown positive correlation of certain parameters with each others like weight shows correlation with serum cholesterol, LDL and total lipid, LDL shows correlation with diastolic blood pressure, triglyceride shows correlation with systolic blood pressure while BMI shows negative correlation with HDL.

Key words: Low density lipoprotein (LDL), High density lipoprotein (HDL), Body mass index (BMI)

\section{Article Citation}

$\checkmark \quad$ Ali FY. Trans fatty acid; a confounding risk factor in coronary heart disease. Professional Med J J an-Feb 2013;20(1):035-040.

\section{INTRODUCTION}

The term 'Trans fats' generally refers to a fat that contains one or more fatty acid group in Trans configuration. Fatty acids containing the maximum possible number of hydrogen ions is said to be saturated; otherwise; it is unsaturated to some degree. Trans fat is unsaturated fat. It may be monounsaturated or polyunsaturated. The major dietary sources of trans fatty acids are vegetable oil condensation, solid margarines, crackers, candies, cookies, snack foods, fried foods, baked foods, and other processed foods ${ }^{1}$. It also occur naturally at relatively low levels in meat and dairy products ( 1 to $8 \%)$ as a result of the fermentation process in the animal's rumens ${ }^{2}$.

Metabolic studies have shown that trans fats have adverse effects on blood lipid profile. It increases the plasma low density lipoprotein (LDL), while decreasing high density lipoproteins (HDL). This combined effect altered the ratio of LDL to HDL resulting in an increased risk of coronary heart disease ${ }^{2}$. In a study conducted by Mozaffarian D et, al; indicates that 1.2 million annual myocardial infarctions and deaths from coronary heart disease in the United States occurred due to consumption of trans fats lipid, while the elimination of industrially reduced trans fats might avert coronary heart disease events each year from $6 \%$ to $19 \%$. For these reasons, health authorities worldwide recommend that consumption of trans fat be reduced to trace amounts $1<1 \%$ of total daily energy intake). Trans fats from partially hydrogenated oils are generally considered to be more dangerous than naturally occurring trans fats ${ }^{3}$.

Dietary trans-fatty acids are associated with increased risk of cardiovascular disease and have been implicated in the incidence of obesity ${ }^{4}$. Trans fat exists 
in both either solid or semi solid state has the capability to accumulate in adipose tissues of the body and can cause obesity or weight gain; therefore; It is established that high-fat saturated diets, relative to low-fat diets, induce adiposity and weight gain and hence disturb the normal body mass index (BMI) of an individual ${ }^{5,6}$.

This study trial was carried out in order to determine the effects of prolong consumption of trans fatty acid on fasting lipid profile and BMI in patients suffering from coronary heart disease.

\section{MATERIAL \& METHODS}

This prospective, comparative clinical study was conducted in Shafakhana Sahib az Zaman Medical Hospital, Quetta from April, 2007 to May, 2008 on 50 patients $(n=50)$. The patients were selected from the medical outpatient department. The objective of the study was to find out the correlation between the consumption of trans fatty acid and fasting lipid profile $\&$ body mass index (BMI) in patients suffering from coronary heart disease. The inclusion criteria were the newly diagnosed cases of coronary heart disease of any age and gender, who gave the informed consent. The exclusion criteria were the patients who had prolong history of coronary heart disease and had been treated and adapted the preventive measures.

All the selected patients were subjected to detail history regarding their dietary habits, physical examination like measurement of height and weight to calculate the BMI and collection of fasting venous blood sample to calculate the lipid profile. The main study information was the history of dietespecially the variety of oil/ghee used daily in the preparation of food (Either trans or cis fatty acid). Weight was measured in the upright position to the nearest $0.1 \mathrm{Kg}$ using a calibrated beam scale. Height was measured without shoes to the nearest $0.1 \mathrm{~cm}$ using a calibrated standiometer. Body mass index was calculated by weight in $\mathrm{Kg}$ divided by height in meter square. The lipid profile was assessed by collecting $3 \mathrm{ml}$ of venous blood after 12 hours fasting. These values were recorded according to the standard values.

All the results were recorded on prescribe performa especially designed for it. The parameters of study were, age, gender, height, weight, BMI, socioeconomic group, frequent food used, nutrition, serum cholesterol, LDL, HDL, triglyceride, total lipid and glucose level. The data results were divided into two groups.

Group I: It includes 18 patients, who use the trans fats free oil/ghee.

Group II: It includes 32 patients, who use the trans fatty acid ghee.

The results of the two groups were analysed by comparing the fasting lipid profile and BMI. Chi square test was applied to find the value of significance. The value $<0.05$ was considered to be significant. Finally the correlation of trans fat was done with coronary heart disease.

\section{RESULTS}

This prospective, comparative clinical study trial was conducted on 50 patients $(n=50)$ which revealed that there were 18 females and 32 were males. The patients were divided into group I $(n=18)$ who used trans fats free oil/ ghee, while group II $(n=32)$ who used trans fats containing ghee. The comparison of age, height, weight and BMI was made between the two groups (Table-I). The mean age, height and weight of group I was slightly higher than that of group11, while the BMI was slightly higher in group II.

The mean of serum cholesterol of those patients consuming TFL ghee is $230.06 \pm 7.987$, with minimum serum cholesterol level is $105 \mathrm{mg} / \mathrm{dl}$ and maximum level is $290 \mathrm{mg} / \mathrm{dl}$. The mean of $\mathrm{HDL}$ is $49 \pm 6.345$, where as minimum HDL in blood is $105 \mathrm{mg} / \mathrm{dl}$ and maximum level is $290 \mathrm{mg} / \mathrm{dl}$. The mean 
of LDL is $230.06 \pm 5.765$, whereas minimum level of LDL is $105 \mathrm{mg} / \mathrm{dl}$ while maximum level is $290 \mathrm{mg} / \mathrm{dl}$. The mean of triglyceride is $48.943 \pm$ where minimum level of triglyceride in blood is $41 \mathrm{mg} / \mathrm{dl}$ while maximum level is $65 \mathrm{mg} / \mathrm{dl}$.

The comparison of serum lipid profile and glucose among the two groups were made. It was found that there is a correlation of Trans fats with certain parameters like high density lipoprotein (HDL) and total lipid with $p$-value of $0.027 \& 0.014$ respectively (Normal significant value of 0.05 ). Similarly serum cholesterol and low density lipoprotein (LDL) correlated with trans fats lipid having both $p$ - value of 0.000 (Normal significant value of 0.01 ). There is a correlation among parameters of group | \& || cholesterol and LDL (with significant value of 0.01 ), where as total lipid and HDL (with significant value of 0.05).

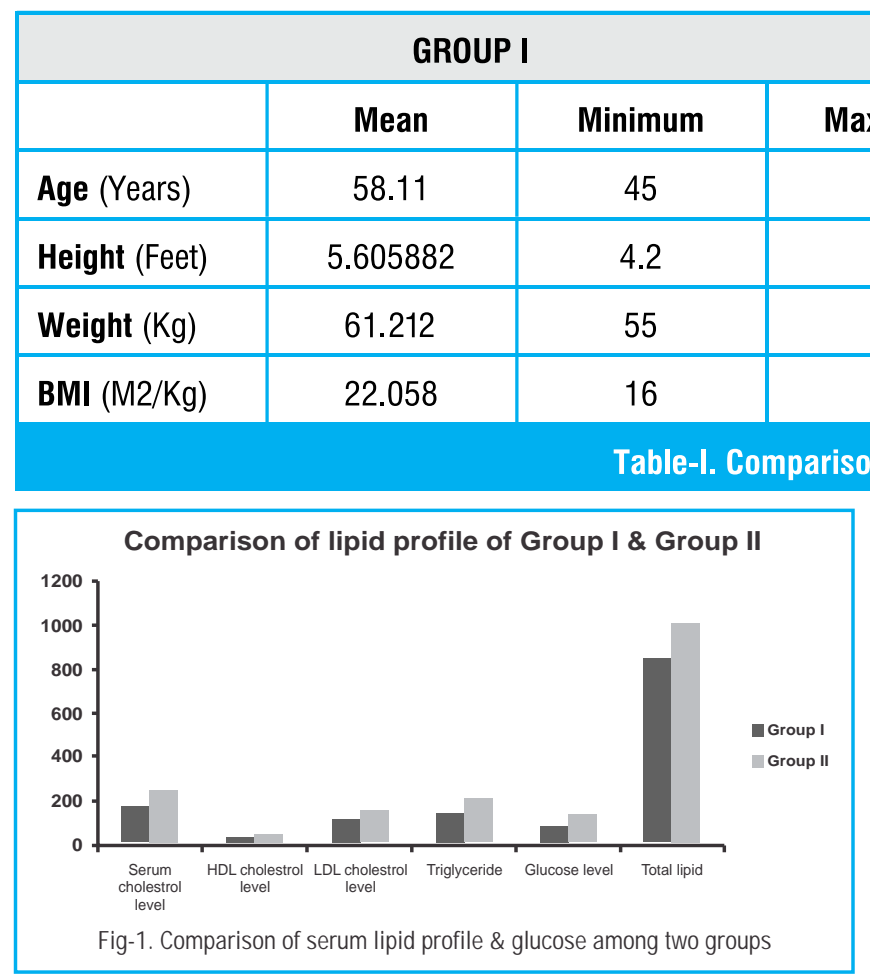

A positive correlation was found among parameters of trans fats consuming subjects where weight was positively correlated with LDL cholesterol, serum cholesterol and total lipids with significant value of $(0.01,0.05,0.05)$ respectively. Similarly BMI was positively correlated with HDL cholesterol with significant value of (0.05), while serum cholesterol shows positive correlation with diastolic BP, LDL cholesterol and glucose level with significant value of $(0.01,0.05,0.05)$ respectively. Whilst HDL cholesterol remain positively correlated with $\mathrm{BMI}(0.05)$ while LDL cholesterol shows positive correlation with diastolic
$B P$, serum cholesterol and glucose level with significant value of $(0.05,0.05,0.01)$ respectively. Similarly triglyceride shows positive correlation with systolic BP and total lipid with significant value of (0.01) and glucose remain positively correlated with diastolic BP, LDL cholesterol and serum cholesterol with significant value of $(0.05,0.01,0.05)$ respectively and total lipid remain positively correlated with triglyceride only with significant value of (0.01).

A positive correlation was found among several parameters of trans fats free subjects in which weight was found positively correlated with systolic BP, diastolic BP, serum cholesterol, triglyceride and total lipid with significant value of $(0.01,0.05,0.05,0.05$, 0.05 ) respectively where as serum cholesterol shows positive correlation with triglyceride, glucose and total lipid with significant value of $(0.01,0.05,0.01)$ respectively, however $\mathrm{HDL}$ cholesterol remain positively correlated with diastolic BP with significant value of (0.05) while triglyceride shows positive correlation with diastolic BP, serum cholesterol and 
total lipid with significant value of $(0.05,0.01,0.01)$ respectively whilst a positive correlation was found among glucose and serum cholesterol with significant value of (0.05). Total lipid shows positive correlation with serum cholesterol and $t$ riglyceride with significantvalue of $(0.01,0.01)$ respectively.

\section{DISCUSSION}

Trans fats are unsaturated fatty acids with at least one double bond in the trans configuration are formed during the partial hydrogenation of vegetable oils, a process that converts vegetable oils into semisolid fats for use in margarines, commercial cooking, and

\begin{tabular}{|l|c|c|c|c|c|c|c|c|c|}
\hline & BMI & $\begin{array}{c}\text { Systolic } \\
\text { BP }\end{array}$ & $\begin{array}{c}\text { Diastolic } \\
\text { BP }\end{array}$ & HDL & LDL & $\begin{array}{c}\text { Serum } \\
\text { cholesterol }\end{array}$ & Triglyceride & $\begin{array}{c}\text { Glucose } \\
\text { level }\end{array}$ & $\begin{array}{c}\text { Total } \\
\text { lipid }\end{array}$ \\
\hline Weight & - & - & - & - & 0.01 & 0.05 & & & 0.05 \\
\hline BMI & - & - & - & 0.05 & & & & & \\
\hline Serum cholesterol & - & - & 0.01 & - & 0.05 & & & 0.05 & \\
\hline HDL & 0.05 & - & - & - & & & & & \\
\hline LDL & - & - & 0.05 & - & & 0.05 & & 0.01 & \\
\hline Triglyceride & - & 0.01 & & - & & & & & 0.01 \\
\hline Glucose Level & - & - & 0.05 & - & 0.01 & 0.05 & & & \\
\hline Total-lipid & - & - & & - & & & 0.01 & & \\
\hline
\end{tabular}

Table-ll. Cross Tabulation Between parameters of trans fats consuming subjects

\begin{tabular}{|l|c|c|c|c|c|c|c|c|c|}
\hline & BMI & $\begin{array}{c}\text { Systolic } \\
\text { BP }\end{array}$ & $\begin{array}{c}\text { Diastolic } \\
\text { BP }\end{array}$ & $\begin{array}{c}\text { Serum } \\
\text { Cholesterol }\end{array}$ & HDL & LDL & Triglyceride & Glucose & Total lipid \\
\hline Weight & - & 0.01 & 0.05 & 0.05 & - & - & 0.05 & - & 0.05 \\
\hline BMI & - & - & - & - & - & - & - & - & \\
\hline Serum cholesterol & - & - & - & - & - & - & 0.01 & 0.05 & 0.01 \\
\hline HDL & - & - & 0.05 & - & - & - & - & - & \\
\hline LDL & - & - & & - & - & - & - & - & \\
\hline Triglyceride & - & - & 0.05 & 0.01 & - & - & - & - & 0.01 \\
\hline Glucose Level & - & - & - & 0.05 & - & - & - & - & \\
\hline Total-lipid & - & - & - & 0.01 & - & - & 0.01 & - & \\
\hline
\end{tabular}

Table-III. Cross Tabulation between parameters of trans fats free subjects

manufacturing processes. From the perspective of the food industry, partially hydrogenated vegetable oils are attractive because of their long shelf life, their stability during deep-frying, and their semi-solidity, which can be customized to enhance the palatability of baked goods and sweets. The average consumption of industrially produced trans fatty acids in the United
States is 2 to 3 percent of total calories consumed ${ }^{7}$. Major sources of trans fats are deep-fried French fries, fast foods, bakery products, packed snack foods, margarines and crackers. Naturally occurring trans fats are consumed in smaller amounts (about 0.5 percent of total energy intake) in meats and dairy products from cows, sheep, and other ruminants; 
these trans fats are produced by the action of bacteria in the ruminant stomach. In our study 32 patients had a history of consumption of trans fats containing ghee.

Trans fats intake has been associated with a higher risk of coronary heart disease. The relation is explained only partially by the adverse effect of these fatty acids on the lipid profile. Approximately 5 to 10 percent of the fat in American diet and about 5 percent of the fat stored in American adipose tissue is trans unsaturated fat. Concerns have been raised for several decades that consumption of Trans fatty acids might have contributed to the 20th century epidemic of coronary heart disease $e^{10,11}$. In our study all the participants selected for study was the diagnosed cases of coronary heartdisease.

The primary health risk identified for trans fat consumption is an elevated risk of coronary heart disease $(\mathrm{CHD})^{11}$. A comprehensive review of studies of trans fats was published in 2006 in the New England J ournal of Medicine that concludes that there is a strong and reliable connection between trans fat consumption and coronary heart disease. The major evidence for the effect of trans fat on coronary heart disease comes from the Nurses' Health Study (NHS) - a cohort study that has been following 120,000 female nurses since its inception in 1976. In this study, $\mathrm{Hu}$ and colleagues analyzed data from 900 coronary events from the NHS population during 14 years of follow up. He determined that a nurse's coronary heart disease risk roughly doubled for each $2 \%$ increase in trans fat calories consumed (instead of carbohydrate calories) $^{8}$. By contrast, it takes more than a $15 \%$ increase in saturated fat calories (instead of carbohydrate calories) to produce a similar increase in risk. Eating non-trans unsaturated fats instead of carbohydrates reduces the risk of coronary heart disease rather than increasing it. Hu also reports on the benefits of reducing trans fat consumption. Replacing $2 \%$ of food energy from trans fat with nontrans unsaturated fats more than halves the risk of $\mathrm{CHD}$
(53\%). By comparison, replacing a larger $5 \%$ of food energy from saturated fat with non-trans unsaturated fats reduces the risk of $\mathrm{CHD}$ by $43 \%$. Another study considered deaths due to coronary heart dis ease, with consumption of trans fats being linked to an increase in mortality, and consumption of polyunsaturated fats being linked to a decrease in mortality ${ }^{12,13}$.

In our study it was revealed that there is a correlation of Trans fatty acid with certain parameters like high density lipoprotein (HDL) and total lipid with p-value of $0.027 \& 0.014$ respectively (Normal significant value of 0.05 ). Similarly serum cholesterol and low density lipoprotein (LDL) correlated with trans fats lipid having both $p$ - value of 0.000 (Normal significant value of 0.01 ). Trans fat behaves like saturated fat by raising the level of LDL, but unlike saturated fat it has the additional effect of decreasing levels of HDL. The net increase in LDL/HDL ratio with Trans fat is approximately double that due to saturated fat. The exact biochemical methods by which Trans fats produce specific health problems are a topic of continuing research $\mathrm{h}^{2,14}$.

\section{CONCLUSIONS}

In conclusion, it is found that the consumption of trans fatty acid is the major contributor of coronary heart diseases because it is responsible in disturbing the ratio of $\mathrm{HDL}$-cholesterol and LDL-cholesterol by increasing the level of LDL-cholesterol(bad cholesterol) and decreasing the level of HDLcholesterol(good cholesterol) hence causing atherosclerosis in arteries. There is a correlation of Trans fatty acid with serum cholesterol, LDL, HDL and total lipid. The consumption of Trans fatty acid has a positive correlation of weight with serum cholesterol, LDL and total lipid, LDL with diastolic blood pressure and triglyceride with systolic blood pressure. There was negative correlation of BMI with HDL. Hence trans fat lipid is a major component of confectionary and tin packed food therefore it can be replace with trans fat free lipid in order to avoid the increasing incidences of 
coronary heartdisease.

6. Clifton PM, Keogh JB, Noakes M. Trans fatty acids in ACKNOWLEDGMENT

I am thankful to Almighty "ALLAH" who is the most Gracious, most Merciful, I am grateful to Surgeon Dr.Mukhtar Mehboob (Shaheed Mohtarma Benazir Bhutto Hospital) who greatly assists me in compilation of this paper through his enthusiastic interest and priceless assistance, I am obliged to Mr. Abrar Hussain Assistant Professor (Biotechnology at BUITEMS) who supervised me on the best of his ability right from beginning of literature site to practical experimentation by his cordial help in conduction and completion of research work and voluminous thesis write-up.

\section{Copyright@ $21 \mathrm{Dec}, 2012$}

\section{REFERENCES}

1. Young Bu, Douglas G. Mashek. Food and Drug Administration, HHS. Food labelling: "Trans fatty acids in nutrition labelling, nutrientcontentclaims, and health claims". Final rule. Fed Regist2002; 133:501-506.

2. Mensink RP, ZockPL, Kester AD, Katan MB. Effects of dietary fatty acids and carbohydrates on the ratio of serum total to HDL cholesterol and on serum lipids and apolipoproteins: a metaanalysis of 60 controlled trials." Am J Clin Nutr 2002; 77: 1146-1155.

3. Mozaffarian D, Katan MB, Ascherio A, Stampfer MJ, Willett WC. Trans fatty acids and cardiovascular disease. $N$ Engl J Med 2006; 354: 1601-1613.

4. Oh K, Hu FB, Manson JE, Stampfer MJ, Willett WC. Dietary fat intake and risk of coronary heart disease in women: 20 years of follow-up of the Nurses' Health Study. AmJ Epidemiol2005: 161:672-679.

5. Saravanan N, Haseeb A, Ehtesham NZ, Ghafoorunissa $X$. Differential effects of dietary saturated and transfatty acids on expression of genes associated with insulin sensitivity in rat adipose tissue". Eur J Endocrinol 2005; 153:159-165. adipose tissue and the food supply are associated $\mathbf{w}$ i t $\mathbf{h}$ myocardial infarction.J Nutr 2004; 134: 874-879.

7. Hunter, JE. Dietary levels of trans fatty acids basis for health concerns and industry efforts to limit. Nutrition Research 2005; 25: 499-513.

8. Oomen CM, Ocke MC, Feskens EJ, Erp-Baart Van MA, Kok FJ , Kromhout D(2001). Association between trans fatty acid intake and 10 -year risk of coronary heart disease in the Zutphen Elderly Study, a prospective population-based study. Lancet2001;357:746-751.

9. Roos N, Schouten E, Katan M. Consumption of a solid fat rich in lauric acid results in a more favourable serum lipid profile in healthy men and women than consumption of a solid fat rich in trans-fatty acids. J Nutr 2001; 131: 242245.

10. Mozaffarian D, Rimm EB, King IB, Lawler RL, McDonald GB, Levy WC. Trans fatty acids and systemic inflammation in heart failure. Am J Clin Nutr 2004; 80:1521- 1525 .

11. Lemaitre RN, King IB, Raghunathan TE, et al. Cell membrane trans-fatty acids and the risk of primary cardiac arrest. Circulation 2002; 105: 697-701.

12. Chavarro J, Stampfer M, Campos H, Kurth T, Willett W Jing Ma. A prospective study of blood Trans fatty acid levels and risk of prostate cancer. Proc. Amer. Assoc. Cancer 2006; 47:161-175.

13. Judd JT, Baer DJ, Clevidence BA, Kris-Etherton $P$, Muesing RA, Iwane $M$. Dietary cis and trans monounsaturated and saturated FA and plasma lipids and lipoproteins in men. Lipids 2002; 37:123-131.

14. Matthan NR, Welty FK, Barrett PH, et al. Dietary hydrogenated fat increases high-density lipoprotein apo A-I catabolism and decreases low-density lipoprotein apoB-100 catabolism in hypercholesterolemic women. Arterioscler Thromb Vasc Biol 2004; 24:10921097.

\author{
AUTHOR(S): \\ MISS FATIMA YOUSAF ALI, \\ BS (Biotechnology), Balochistan IT University \\ Lecturer Zoology \\ Govt. Girls Degree College, Sardar Hassan Musa Quetta
}

\section{CORRESPONDENCE ADDRESS:}

Miss Fatima Yousaf Ali

H.No. 7-70/3 A Alamdar Road Mari abad Quetta attia.attia53@yahoo.com
Article received on: $11 / 08 / 2012$ Accepted for Publication: 21/12/2012 Received after proof reading: $\quad$ 2/101/2013 